\title{
Metachronous metastasis- and survival-analysis show prognostic importance of lymphadenectomy for colon carcinomas
}

Tilman Laubert $^{*}$, Jens K Habermann ${ }^{1}$, Claudia Hemmelmann², Markus Kleemann', Elisabeth Oevermann', Ralf Bouchard', Philipp Hildebrand ${ }^{1}$, Thomas Jungbluth ${ }^{1}$, Conny Bürk${ }^{1}$, Hamed Esnaashari ${ }^{1}$, Erik Schlöricke ${ }^{1}$, Martin Hoffmann ${ }^{1}$, Andreas Ziegler ${ }^{2}$, Hans-Peter Bruch ${ }^{1}$ and Uwe J Roblick ${ }^{1}$

\begin{abstract}
Background: Lymphadenectomy is performed to assess patient prognosis and to prevent metastasizing. Recently, it was questioned whether lymph node metastases were capable of metastasizing and therefore, if lymphadenectomy was still adequate. We evaluated whether the nodal status impacts on the occurrence of distant metastases by analyzing a highly selected cohort of colon cancer patients.

Methods: 1,395 patients underwent surgery exclusively for colon cancer at the University of Lübeck between 01/ 1993 and 12/2008. The following exclusion criteria were applied: synchronous metastasis, R1-resection, prior/ synchronous second carcinoma, age $<50$ years, positive family history, inflammatory bowel disease, FAP, HNPCC, and follow-up $<5$ years. The remaining 421 patients were divided into groups with $(T M+, n=75)$ or without (TM-, $n=346$ ) the occurrence of metastasis throughout a 5 -year follow-up.

Results: Five-year survival rates for TM + and TM- were $21 \%$ and $73 \%$, respectively $(p<0.0001)$. Survival rates differed significantly for N0 vs. N2, grading 2 vs. 3, UICC-I vs. -II and UICC-I vs. -III ( $p<0.05)$. Regression analysis revealed higher age upon diagnosis, increasing $\mathrm{N}$ - and increasing T-category to significantly impact on recurrence free survival while increasing $\mathrm{N}$-and T-category were significant parameters for the risk to develop metastases within 5-years after surgery (HR 1.97 and 1.78; $\mathrm{p}<0.0001$ ).

Conclusions: Besides a higher T-category, a positive N-stage independently implies a higher probability to develop distant metastases and correlates with poor survival. Our data thus show a prognostic relevance of lymphadenectomy which should therefore be retained until conclusive studies suggest the unimportance of Imyphadenectomy.
\end{abstract}

Keywords: Colon cancer, Lymph nodes, Metastasis, Prognosis, Survival, Recurrence free survival, Regression analysis

\section{Background}

Colon cancer is one of the most common malignant tumor entities in Europe and North America [1]. Patients with synchronous distant metastasis have a significantly worse prognosis than patients diagnosed with localized disease. Despite an increasing motivation to undergo routine screening about $20 \%$ of all patients are diagnosed at an advanced tumor stage with manifest

\footnotetext{
* Correspondence: tlaubert@googlemail.com

'Department of Surgery, Laboratory for Surgical Research, University of

Lübeck, Ratzeburger Allee 160, D-23538 Lübeck, Germany

Full list of author information is available at the end of the article
}

metastases (Union Internationale Contre le Cancer (UICC) stage IV). These patients face a 5-year survival rate of around $10 \%[2,3]$. Approximately $40 \%$ of patients who initially present without distant tumor growth (UICC stage II and III) will later on suffer from local or distant recurrence [4]. Unfortunately, it still remains clinically impossible to individually predict which patients are more likely to develop distant recurrence after resection of the primary carcinoma.

Colon cancer is staged according to the American Joint Committee of Cancer (AJCC) TNM staging system which reflects tumor invasion, lymph node involvement

\section{Biomed Central}


and existence of distant metastases. Extended lymphadenectomy has long been established as the standard oncologic resection of colon cancer [5]. Hereby, the Ncategory not only implies the possible indication for an adjuvant treatment in colon cancer but also constitutes an important prognostic factor: different groups have shown a survival benefit for patients with UICC-III and even -II if an extensive dissection and evaluation of harvested lymph nodes were performed [1,6,7]. In contrast, other studies suggest that lymph node dissection might be of minor or no prognostic impact and - potentially should be omitted: Wong et al. analyzed a cohort of 30,625 colon cancer patients and showed that survival was not significantly different when a median of 6 versus 13 lymph nodes were dissected [8]. Based on an analysis of 16,129 patients Hölzel et al. revealed that the number of positive lymph nodes and occurrence of distant metastases do not correlate [3]. Furthermore, they presented a conclusive statistical model suggesting that lymph node metastases are not capable to set distant metastases. Consequently, they concluded that lymph node resection might be of less clinical importance than currently considered and potentially reflect "overtreatment" $[3,9]$. One could therefore speculate that similar to the past development of clinical pathways for surgical breast cancer treatment, lymph node resection in colon cancer could soon be performed according to a sentinel concept instead of comprehensive lymphadenectomy as performed today [10].

While many studies do not distinguish between carcinomas of the rectum and the colon, both need to be accounted as different entities regarding anatomic routs of metastasizing, prognosis and therapeutic regimes. In order to determine accurate prognosis and survival rates we therefore considered it necessary to distinguish between both entities and focused exclusively on colon carcinomas in this study. Furthermore, we excluded patients who might bias the analysis due to clinical features known to impact on prognosis: e.g., pre-existing chronic inflammatory bowel disease [11], hereditary colorectal cancer $[12,13]$, and residual tumor tissue after surgical resection [14].

Due to the strict selection of our patient cohort, this study design not only allowed determining the most influencing prognostic factors in a highly selected cohort of colon cancer patients. It was furthermore possible to evaluate the impact of a positive lymph node status on the subsequent development of distant metastases and survival outcome.

\section{Methods}

\section{Patients}

This study encompassed 1,395 patients who underwent surgery for colon cancer at the Department of Surgery,
University Clinic Schleswig-Holstein, Campus Lübeck, Germany, between January 1993 and December 2008. Prospectively documented demographic, clinical and follow-up data were obtained after patients' informed consent and in accordance to the approval of the local Ethical Committee (\#07-124). We excluded patients from the cohort of 1,395 patients who had not completed an in-house follow-up of at least 5 years unless an event of either death or diagnosis of metastasis occurred. Thus, median follow-up for the entire collective was 73.6 months (range 1.1-215.5 months). In addition, patients younger than 50 years and patients with synchronous metastases were excluded. "Synchronous metastasis" and "synchronous second carcinoma"were defined as the diagnosis of a distant metastasis or second carcinoma together with or within a threemonth interval of the diagnosis of the primary colon cancer. "Metachronous"was defined as an occurrence after a period of three months postoperatively. Additional exclusion criteria known to bias data analysis regarding metastasizing, survival and prognosis of colon cancer were applied (Figure 1). Subsequently, we categorized the remaining patients into those who did develop distant metastasis $(\mathrm{TM}+, \mathrm{n}=75)$ or who did not (TM-, $\mathrm{n}=346$ ) within a 5 -year follow-up. UICC/ AJCC stages were defined according to the consensus of 1997 [15].

\section{Statistics}

Continuous variables were expressed as mean \pm standard deviation and categorical variables as percent. The Kaplan-Meier curves for TM + vs. TM-, grading 1-3, UICC stage I-IV, N-status $0-2$ and right vs. left colon were calculated and assessed for significance by the logrank test. The 5-year survival rates were estimated with the Kaplan-Meier method. The 95\% confidence intervals and the p-values were based on an asymptotic approach by using the standard normal distribution. In addition, a Cox regression backwards selection model was used to investigate the effect of clinical and demographic parameters upon recurrence free survival and the occurence of metastasis. For this analysis, initially all variables (sex, age, N-category, T-category, UICC-stage and tumor grading) were taken into account and variables with the highest $\mathrm{p}$-value (for $\mathrm{p}>0.1$ ) were excluded subsequently. All results were considered significant with $p<$ 0.05. All calculations were performed using SAS software version 9.2 .

\section{Results}

\section{Patient cohorts}

We identified 2,570 patients from our colorectal cancer database who underwent surgery between January 1993 and December 2008. Of those, 1,395 were colon cancer 


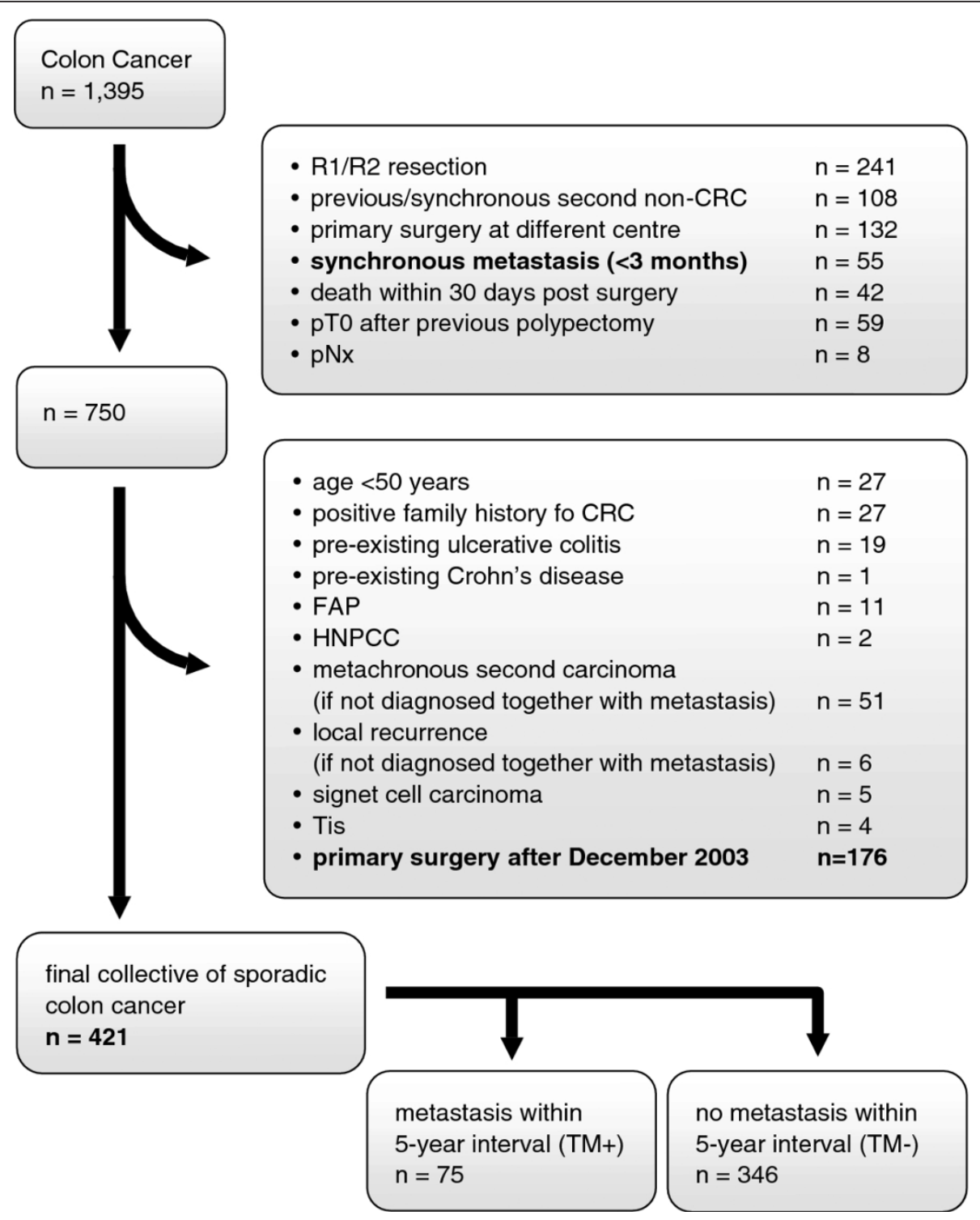

Figure 1 Exclusion criteria for patients who underwent surgery for Colon Cancer. The listed exclusion criteria were applied subsequently. CRC: Colorectal cancer, FAP: Familial Adenomatous Polyposis, HNPCC: Heriditary Non-Polyposis Colon Cancer, Tis: Carcinoma in situ.

patients. The application of exclusion criteria resulted in a collective of 421 patients with 75 presenting with subsequent, metachronous metastasis $(\mathrm{TM}+)$ and 346 without (TM-) (Figure 1). Overall, ninety-six patients were staged UICC I, 182 patients UICC II and 143 patients UICC III. For N-stage, there were 278 patients with N0, 92 patients with $\mathrm{N} 1$ and 51 patients with N2. For tumor grading, 11 patients presented with G1, 321 patients with G2 and 89 patients with G3. When considering the cohorts of TM + and TM-, both groups presented with comparable clinico-pathological parameters except for differences in T-category, N-category, UICC-stage and age with a higher age in the TM- cohort (Table 1).

\section{Survival analysis}

Overall, the 5-year survival rates showed significant differences between UICC stages I and II $(\mathrm{p}=0.0001)$ and between stages I and III ( $p=0.0002$, Table 2 ). KaplanMeier survival estimation showed significant differences for the three-group comparison of UICC-I, -II and -III (Figure 2b).

The 5-year survival rates for $\mathrm{N}$-categories were $66 \%$ for N0 (95\%CI $60-71 \%), 64 \%$ for N1 (95\%CI 53-73\%) and $49 \%$ for N2 (95\% CI 35-62\%), respectively. A significant difference was found for the comparison between $\mathrm{N} 0$ vs. N2 ( $\mathrm{p}=0.023)$. In line with these results, Kaplan-Meier survival estimation showed a significant 
Table 1 Demographic and clinical data for the cohort which developed metastases within a 5-year interval after primary resection (TM+) and which did not (TM-)

\begin{tabular}{|c|c|c|c|}
\hline Variable & $T M+(n=75)$ & TM- $(n=346)$ & p-value \\
\hline Age [years (SD)] & $68.7(10.1)$ & $71.5(10.2)$ & 0.0222 \\
\hline Sex & & & 0.4453 \\
\hline female & 35 (46.7\%) & $180(52.0 \%)$ & \\
\hline male & 40 (53.3\%) & 166 (48.0\%) & \\
\hline Localization & & & 0.7023 \\
\hline right & 34 (45.3\%) & $168(48.6 \%)$ & \\
\hline left & 41 (54.7\%) & $178(51.4 \%)$ & \\
\hline T-stage & & & $<0.0001$ \\
\hline 1 & $2(2.7 \%)$ & $34(9.8 \%)$ & \\
\hline 2 & $4(5.3 \%)$ & 66 (19.1\%) & \\
\hline 3 & 55 (73.3\%) & 21 (60.1\%) & \\
\hline 4 & $14(18.7 \%)$ & 35 (10.0\%) & \\
\hline $\mathrm{N}$-stage & & & $<0.0001$ \\
\hline 0 & 29 (38.7\%) & 249 (72.0\%) & \\
\hline 1 & $24(32.0 \%)$ & 68 (19.6\%) & \\
\hline 2 & 22 (29.3\%) & 29 (8.4\%) & \\
\hline \multicolumn{4}{|l|}{ Grading } \\
\hline 1 & $1(1.3 \%)$ & $10(2.9 \%)$ & 0.5098 \\
\hline 2 & 55 (73.4\%) & 266 (76.9\%) & \\
\hline 3 & 19 (25.3\%) & $70(20.2 \%)$ & \\
\hline UICC-stage & & & $<0.0001$ \\
\hline 1 & $5(6.7 \%)$ & 91 (26.3\%) & \\
\hline 2 & 24 (32.0\%) & $158(45.7 \%)$ & \\
\hline 3 & 46 (61.3\%) & 97 (28.0\%) & \\
\hline
\end{tabular}

Continuous variables are expressed as mean (standard deviation) and categorical variables as number (percent). SD: standard deviation. Significant $\mathrm{p}$-values are highlighted in bold

difference exclusively for the comparison of N0 versus N2 (Figure 2c and 2d).

The 5-year survival rates for tumor grading were $73 \%$ for grading 1 (95\%CI $37-90 \%), 67 \%$ for grading 2 (95\% CI, $61-72 \%)$ and $52 \%$ for grading 3 (95\%CI $41-61 \%$ ), respectively, with a significant difference between grading 2 and $3(\mathrm{p}=0.0113)$. The 5 -year survival rates for right vs. left colon were 59\% (95\%CI 52-65\%) and 68\% (95\%CI 61-74\%) and did not differ significantly.

When considering the cohorts of TM + and TM-, patients with TM- presented with a significantly higher 5 -year survival rate $(73 \%$; $95 \%$ CI $68-77 \%)$ compared to those with $\mathrm{TM}+(21 \%$; $95 \% \mathrm{CI} 13-31 \%)$, as expected (p $<0.0001$, Table 2). These results were reflected by Kaplan-Meier survival estimation which showed significant differences for group comparison of $\mathrm{TM}+$ versus TM- (Figure 2a).

Recurrence free survival and metachronous metastases In order to determine demographic and clinical parameters with significant impact on recurrence free
Table 2 5-year survival rates (SR) and statistical analyses for comparison of distinct groups of colon cancer patients.

\begin{tabular}{|c|c|c|c|c|}
\hline Variable & $\begin{array}{l}5 \text {-year } \\
\text { SR }\end{array}$ & $\begin{array}{l}95 \% \\
\mathrm{Cl}\end{array}$ & $\begin{array}{l}\text { p-value } \\
\text { (comparison) }\end{array}$ & \\
\hline \multicolumn{5}{|l|}{ Metastasis } \\
\hline $\begin{array}{l}\text { yes (TM } \\
+)\end{array}$ & $73 \%$ & $68-77 \%$ & $<0.0001$ & \\
\hline no (TM-) & $21 \%$ & $13-31 \%$ & & \\
\hline \multicolumn{5}{|c|}{ Grading } \\
\hline 1 & $73 \%$ & $37-90 \%$ & 0,6578 (1 vs 2) & \\
\hline 2 & $67 \%$ & $61-72 \%$ & & $\begin{array}{l}0.1449 \text { (1 vs } \\
3)\end{array}$ \\
\hline 3 & $52 \%$ & $41-61 \%$ & $\mathbf{0 . 0 1 1 3}$ (2 vs 3) & \\
\hline \multicolumn{5}{|l|}{$\mathrm{N}$-stage } \\
\hline 0 & $66 \%$ & $60-71 \%$ & 0.7206 (0 vs 1) & \\
\hline 1 & $64 \%$ & $53-73 \%$ & & $\begin{array}{l}0.0230 \text { (0 vs } \\
2)\end{array}$ \\
\hline 2 & $49 \%$ & $35-62 \%$ & 0.0790 (1 vs 2) & \\
\hline \multicolumn{5}{|l|}{ UICC stage } \\
\hline 1 & $80 \%$ & $71-87 \%$ & 0,0001 (I vs II) & \\
\hline$\|$ & $59 \%$ & $51-66 \%$ & & $\begin{array}{l}0.0002 \text { (I vs } \\
\text { III) }\end{array}$ \\
\hline III & $59 \%$ & $50-66 \%$ & 0.9928 (II vs III) & \\
\hline \multicolumn{5}{|l|}{ Localization } \\
\hline right & $59 \%$ & $52-65 \%$ & 0.0512 & \\
\hline left & $68 \%$ & $61-74 \%$ & & \\
\hline
\end{tabular}

"Metastasis"implies the occurrence of a distant metastasis within a 5-year interval after primary surgery. 5-year SR: 5-year survival rate; $95 \% \mathrm{Cl}: 95 \%$ confidence interval. $\alpha=0.05$. Significant $p$-values are highlighted in bold

survival we performed a Cox regression backwards analysis taking sex, age, N-category, T-category, UICC-stage and tumor grading into account. This revealed an increasing T-category $(\mathrm{HR}=1.84, \mathrm{p}<0.0001)$, increasing $\mathrm{N}$-category $(\mathrm{HR}=1.26, \mathrm{p}=0.033)$ and male sex $(\mathrm{HR}=1.04, \mathrm{p}=<0.0001)$ as significant parameters with a negative impact on recurrence free survival (Table 3).

Furthermore, we aimed to identify parameters influencing the occurrence of distant metastases. Here, Cox regression backwards selection revealed a significant relevance of an increasing $\mathrm{N}$-category $(\mathrm{HR}=1.97, \mathrm{p}=$ $0.0001)$ and an increasing T-category $(\mathrm{HR}=1.78, \mathrm{p}=$ 0.0028 ) for the occurrence of metachronous distant metastases (Table 4).

\section{Discussion}

This study evaluates survival and probability for the occurrence of metachronous colon cancer metastasis. For the first time, such an analysis was performed in a highly selected cohort of patients with sporadic colon cancer that passed thorough exclusion criteria. Known clinical parameters were confirmed to be of significant impact for patients' prognosis such as sex, T- and $\mathrm{N}$-category. Furthermore, Cox regression analysis 


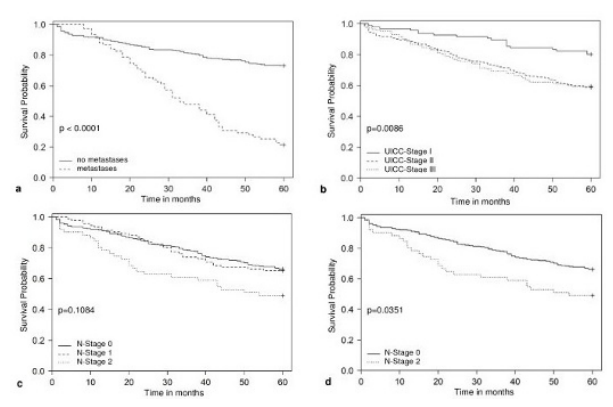

Figure 2 Kaplan Meier survival curves for the cohorts a) TMversus $\mathrm{TM}+$, b) UICC-stage I versus II versus III, c) $\mathrm{N}$-stage 0 versus 1 versus 2 and d) $\mathrm{N}$-stage 0 vs. 2. Significance was determined using logrank-test.

revealed a significant impact of $\mathrm{T}$ - and $\mathrm{N}$-category on survival as well as a significant impact of $\mathrm{N}$-category on the risk to develop metachronous metastasis. Only few other studies have performed Cox regression analyses for the same endpoints "survival" and "metachronous metastasis". However, none of these studies was based on a collective with such stringent inclusion criteria $[16,17]$.

Several studies have shown a survival benefit for patients with an extensive examination of lymph nodes for both UICC II and UICC III stage cancers $[1,6,7]$. The current North American consensus and the German AWMF guidelines demand at least 12 lymph nodes to be retrieved and examined in order to accurately determine the stage of colon cancer $[18,19]$. However, besides the surgical technique the lymph node yield depends on a variety of variables such as age, immuneresponse, investigation techniques and tumor location [20]. Despite earlier reports that prognosis improves with increasing lymph node count, the relationship between lymph node yield and survival is not understood and may not be causal but merely statistical in nature. There has been no proof so far that distant metastases can derive from lymph node metastases. The association of tumor-positive lymph nodes with the occurrence of distant metastasis has so far been based on statistical measures and the same accounts for

Table 3 Results of the Cox regression backwards selection analysis for recurrence free survival within a 5year interval

\begin{tabular}{llll}
\hline Variable & Hazard Ratio & $\mathbf{9 5 \% ~ C l}$ & p-value \\
\hline sex & 1.040 & $1.024-1.057$ & $\mathbf{0 . 0 3 3}$ \\
N-category & 1.261 & $1.019-1.560$ & $<\mathbf{0 . 0 0 0 1}$ \\
T-stage & 1.838 & $1.422-2.375$ & $<\mathbf{0 . 0 0 0 1}$ \\
\hline
\end{tabular}

Sex, age, N-stage, T-stage, UICC-stage and grading were taken into account. The Hazard Ratio implies a decrease in risk for the female sex and an increase in risk with each additional year of age and for an increase T-stage, given that the other two variables remain constant improved survival with an increase of lymph nodes dissected. Still, adequate resection of lymph nodes is also performed in order to control local recurrence as well, especially in stage III colon cancer patients. Studies have shown a survival benefit for patients undergoing complete mesocolic excision which does not imply a particular number of resected lymph nodes but rather aims at the most radical dissection of lymph nodes possibly involved $[21,22]$. The detection of micro metastases and its association with worse prognosis in terms of occurrence of distant metastases and survival may also not be causal, especially since other studies described contradictory results $[23,24]$. In fact, several in-vitro and invivo studies support the idea that lymph node metastases are themselves not lethal and that surgical lymph node removal should be de-emphasized or omitted [9]. On the other hand, epithelial-mesenchymal transition (EMT) of tumor cells, a process of great importance for the development of distant metastases, is reversed in the metastasis itself (mesenchymal-epithelial transition, MET). After a certain time, cells at the invasive front of the metastasis may repeatedly undergo EMT thus emphasizing their ability to disseminate and metastasize subsequently [25].

Currently, there are no randomized trials or meta-analyses demonstrating a survival benefit of an extensive lymph node dissection in colon cancer. The relevance of radical lymph node dissection has been questioned by other authors [26] and for some tumor entities the extent of radical lymph node dissection was diminished on the basis of clinical studies [27,28]. Based on the colon cancer cohort of the Tumor Registry Munich, Hölzel et al. stated that the risk to develop distant metastases does not correlate with the detection of positive lymph nodes [3]. They also concluded that positive lymph nodes that were not dissected would not contribute to a subsequent occurrence of distant metastases. An important assumption in their conclusions was, however, that a given tumor grows with a constant kinetic. In contrast, our results revealed that besides Tcategory, particularly $\mathrm{N}$-category is an independent factor with significant impact on the formation of distant metastases.

Table 4 Results of the Cox regression backwards selection analysis for the occurrence of distant metastases within a 5-year interval

\begin{tabular}{llll}
\hline Variable & Hazard Ratio & $\mathbf{9 5 \% ~ C l}$ & p-value \\
\hline N-stage & 1.97 & $1.49-2.60$ & $\mathbf{0 . 0 0 0 1}$ \\
T-stage & 1.78 & $1.22-2.60$ & $\mathbf{0 . 0 0 2 8}$ \\
\hline
\end{tabular}

Sex, age, N-stage, T-stage, UICC-stage and grading were taken into account. The Hazard Ratio implies an increase in risk for an increase in N- and T-stage, given that the other variable remains constant 
Many clinical parameters have been described which influence the prognosis of colon cancer. Residual tumor mass (R1 or R2 resection) after removal of the primary malignancy implies a significantly worse prognosis than R0-resected cancers [14]. Inflammatory bowel disease (IBD)-associated colon carcinomas have a worse outcome than colon cancer in patients without IBD [11,29]. Also, hereditary colorectal cancer differs in its prognosis from sporadic colorectal cancer $[12,13]$. Most studies regarding outcome of colon cancer analyzed large cohorts without exclusion of patients with clinical features known to have an impact on prognosis. Wang et al. excluded patients with prior malignancies, carcinomas located more distally than the recto-sigmoid and those with a histology other than signet cell, mucinous or adenocarcinomas and analyzed a collective of 24,477 CRC patients for lymph node yield and prognosis [30]. They did not exclude patients with potential hereditary malignant disease or IBD. Hashiguchi et al. excluded patients with multiple colon cancers, patients with another synchronous malignancy and patients with a diagnosed polyposis. They analyzed the prognostic significance of the number of lymph nodes examined in colon cancer and included 859 patients from a single centre [31]. In our study we performed all analyses in a thoroughly selected patient cohort thereby minimizing the bias arising from a large but heterogeneous collective. Additionally, in order to address the issue of metachronous distant metastases in relation to the status of lymph nodes dissected during primary surgery we excluded patients who had not completed a 5-year follow-up. Patients who underwent primary resection of colon cancer at a different center were also excluded in order to eliminate possible inter-center variability of patients' prognosis [32].

We found significant differences in survival only for some of the given categories within each parameter such as the difference for N0 versus N2 and grading G2 versus G3. We have to acknowledge the possibility that the lack of significant differences for all categories may be due to the small size of our cohorts. On the other hand, none of the studies showing significant differences for all categories had patients as strictly selected. The cohorts of TM + and TM- differed significantly in Tcategory, N-category, UICC-stage and age. The difference in age might have biased the results. However, since the TM- cohort was on average older while presenting better survival we argue that the difference is valid and might in fact be larger. The problem of differences in the other variables was addressed by Cox regression analysis. Cox regression analysis showed that $\mathrm{T}$-category and $\mathrm{N}$-category besides sex were parameters with significant impact on 5-year recurrence free survival. Generally, an increase in both $\mathrm{N}$ - and T-category is known to be associated with worse prognosis [3]. Only for the regression analysis we used recurrence free survival. For the calculation of survival curves we used overall survival. We have to take into consideration that in this context, analyses of overall survival certainly have shortcomings in comparison to disease specific survival. In order to avoid this dilemma, we limited the survival comparisons to a 5-year interval by censoring all patients with later events. For this period, we estimate the mortality to be primarily related to the pre-existing malignancy.

Our Cox regression analysis revealed that both $\mathrm{N}$ - and $\mathrm{T}$-category are parameters with significant impact on the risk to develop distant metastases. Several studies have performed Cox regression analyses with hazard ratios given for each category, i.e. N1 versus $\mathrm{N} 2$ and versus N3 [3]. Only a few studies included Cox regression analyses in order to determine which pathological and demographic parameters have the highest impact on the endpoints "death" and "occurrence of a metachronous distant metastasis". Ikeguchi et al. investigated 282 patients with regard to survival and occurrence of metachronous metastases and a possible correlation with various clinic-pathological and cytometric parameters [17]. Lymph node status, tumor location (rectum/colon) and lymphatic invasion were significant factors in logistic regression analysis affecting metachronous hematogenic metastases whereas $\mathrm{T}$-category and ploidy status were not. However, the only exclusion criterion for the collective was adjuvant chemo- or radiochemotherapy [17]. Heinzerling et al. analyzed 51 distinct clinicopathological parameters addressing the question of metachronous metastasis occurrence [16]. In their multivariate analysis only alcohol intake, patients undergoing abdomino-perineal resection and the use of angiotensin-converting enzyme inhibitor were significantly associated with development of distant disease relapse. In their univariate analysis, however, the dissection of fewer lymph nodes was associated with development of metastasis. The study collective consisted of only 55 patients with carcinoma of both the rectum and the colon and $96 \%$ of the patients were males. UICC II stage was the only inclusion criteria and follow-up was three years.

\section{Conclusion}

Much like previous studies we cannot provide any proof for a causal association of lymph node status and a subsequent metastasis. However, our regression analysis shows that lymph node status is of independent prognostic impact for the occurrence of distant metastasis in colon cancer patients. In light of our study, previous clinical studies and molecular investigations it is reasonable to assume that lymph nodes are able to set distant 
metastases. We therefore suggest that standard dissection of lymph nodes in patients with colon cancer should be continued until further studies suggest otherwise.

\section{Acknowledgements}

We gratefully thank Claudia Killaitis for IT support. Grants from the Werner and Clara Kreitz Foundation, the Ad Infinitum Foundation and the German Cancer Aid Foundation are gratefully acknowledged. This study was performed in connection with the Surgical Center for Translational Oncology Lübeck (SCTO-L) and the North German Tumorbank of Colorectal Cancer (Deutsche Krebshilfe \#108446).

\section{Author details}

'Department of Surgery, Laboratory for Surgical Research, University of Lübeck, Ratzeburger Allee 160, D-23538 Lübeck, Germany. ${ }^{2}$ Institute of Medical Biometry and Statistics, University of Lübeck, Maria-Goeppert-Straße 1, D-23562 Lübeck, Germany.

\section{Authors' contributions}

$T L, J H, M K$ : Conception and design of study. TL, JH, EO, RB, PH, TJ, HE: Acquisition of data. $C H, A Z, T L, J H, C B, M H$, UR: Analysis and interpretation of data. TL, TJ, ES, JH, UR, CB, PH, UR, HB: Drafting and revising of manuscript. All authors: Approval of manuscript version to be published.

\section{Competing interests}

The authors declare that they have no competing interests.

Received: 5 December 2011 Accepted: 23 March 2012

Published: 23 March 2012

\section{References}

1. Johnson PM, Porter GA, Ricciardi R, Baxter NN: Increasing negative lymph node count is independently associated with improved long-term survival in stage IIIB and IIIC colon cancer. J Clin Oncol 2006, 24(22):3570-3575.

2. Jemal A, Siegel R, Ward E, Hao Y, Xu J, Murray T, Thun MJ: Cancer statistics, 2008. CA Cancer J Clin 2008, 58(2):71-96.

3. Holzel D, Eckel R, Engel J: Colorectal cancer metastasis. Frequency, prognosis, and consequences. Chirurg 2009, 80(4):331-340.

4. Weitz J, Koch M, Debus J, Hohler T, Galle PR, Buchler MW: Colorectal cancer. Lancet 2005, 365(9454):153-165.

5. Bruch HP, Schwandner O, Schiedeck TH, Roblick UJ: Actual standards and controversies on operative technique and lymph-node dissection in colorectal cancer. Langenbecks Arch Surg 1999, 384(2):167-175.

6. Sarli L, Bader G, lusco D, Salvemini C, Mauro DD, Mazzeo A, Regina G, Roncoroni L: Number of lymph nodes examined and prognosis of TNM stage II colorectal cancer. Eur J Cancer 2005, 41(2):272-279.

7. Chang GJ, Rodriguez-Bigas MA, Skibber JM, Moyer VA: Lymph node evaluation and survival after curative resection of colon cancer: systematic review. J Natl Cancer Inst 2007, 99(6):433-441.

8. Wong SL, Ji H, Hollenbeck BK, Morris AM, Baser O, Birkmeyer JD: Hospital lymph node examination rates and survival after resection for colon cancer. JAMA 2007, 298(18):2149-2154.

9. Cady B: Regional lymph node metastases; a singular manifestation of the process of clinical metastases in cancer: contemporary animal research and clinical reports suggest unifying concepts. Ann Surg Oncol 2007, 14(6):1790-1800

10. Oltedal S, Gilje B, Korner H, Aasprong OG, Tjensvoll K, Heikkila R, Smaaland $R$, Nordgard O: Detection of occult metastases in sentinel lymph nodes from colon cancer patients by K-ras mutation peptide nucleic acid clamp PCR. Ann Surg 2010, 251(6):1087-1091.

11. Habermann JK, Upender MB, Roblick UJ, Kruger S, Freitag S, Blegen $H$, Bruch HP, Schimmelpenning H, Auer G, Ried T: Pronounced chromosomal instability and multiple gene amplifications characterize ulcerative colitis-associated colorectal carcinomas. Cancer Genet Cytogenet 2003, 147(1):9-17.
12. Birgisson H, Ghanipour A, Smedh K, Pahlman L, Glimelius B: The correlation between a family history of colorectal cancer and survival of patients with colorectal cancer. Fam Cancer 2009, 8(4):555-561.

13. Chan JA, Meyerhardt JA, Niedzwiecki D, Hollis D, Saltz LB, Mayer RJ, Thomas J, Schaefer P, Whittom R, Hantel A, et al: Association of family history with cancer recurrence and survival among patients with stage III colon cancer. JAMA 2008, 299(21):2515-2523.

14. Wittekind C, Compton CC, Greene FL, Sobin LH: TNM residual tumor classification revisited. Cancer 2002, 94(9):2511-2516.

15. Fleming I, Cooper J, Henson DE, et al: AJCC Cancer Staging Manual. Philadelphia, New York: Lippincot-Raven; 51997.

16. Heinzerling JH, Anthony T, Livingston EH, Huerta S: Predictors of distant metastasis and mortality in patients with stage II colorectal cancer. Am Surg 2007, 73(3):230-238

17. Ikeguchi M, Sakatani T, Endo K, Makino M, Kaibara N: Computerized nuclear morphometry is a useful technique for evaluating the high metastatic potential of colorectal adenocarcinoma. Cancer 1999, 86(10):1944-1951.

18. FACS: viewed on May 20th, 2011, 10:00 am EST.[http://www.facs.org/ cancer/qualitymeasures.html].

19. Schmiegel W, Reinacher-Schick A, Arnold D, Graeven U, Heinemann V, Porschen R, Riemann J, Rodel C, Sauer R, Wieser M, et al: Update S3guideline "colorectal cancer" 2008. Z Gastroenterol 2008, 46(8):799-840.

20. Chou JF, Row D, Gonen M, Liu YH, Schrag D, Weiser MR: Clinical and pathologic factors that predict lymph node yield from surgical specimens in colorectal cancer: a population-based study. Cancer 2010, 116(11):2560-2570.

21. West NP, Hohenberger W, Weber K, Perrakis A, Finan PJ, Quirke P: Complete mesocolic excision with central vascular ligation produces an oncologically superior specimen compared with standard surgery for carcinoma of the colon. J Clin Oncol 2010, 28(2):272-278.

22. Pramateftakis MG: Optimizing colonic cancer surgery: high ligation and complete mesocolic excision during right hemicolectomy. Tech Coloproctol 2010, 14:(Suppl 1):S49-51.

23. van Schaik PM, Hermans E, van der Linden JC, Pruijt JR, Ernst MF, Bosscha K: Micro- metastases in stages I and II colon cancer are a predictor of the development of distant metastases and worse disease-free survival. Eur $\rfloor$ Surg Oncol 2009, 35(5):492-496.

24. Oberg A, Stenling R, Tavelin B, Lindmark G: Are lymph node micrometastases of any clinical significance in Dukes Stages A and B colorectal cancer? Dis Colon Rectum 1998, 41(10):1244-1249.

25. Brabletz T, Jung A, Spaderna S, Hlubek F, Kirchner T: Opinion: migrating cancer stem cells - an integrated concept of malignant tumour progression. Nat Rev Cancer 2005, 5(9):744-749.

26. Gervasoni JE Jr, Sbayi S, Cady B: Role of lymphadenectomy in surgical treatment of solid tumors: an update on the clinical data. Ann Surg Oncol 2007, 14(9):2443-2462.

27. Rudenstam CM, Zahrieh D, Forbes JF, Crivellari D, Holmberg SB, Rey $P$, Dent D, Campbell I, Bernhard J, Price KN, et al: Randomized trial comparing axillary clearance versus no axillary clearance in older patients with breast cancer: first results of International Breast Cancer Study Group Trial 10-93. J Clin Oncol 2006, 24(3):337-344.

28. Morton DL, Thompson JF, Cochran AJ, Mozzillo N, Elashoff R, Essner R, Nieweg OE, Roses DF, Hoekstra HJ, Karakousis CP, et al: Sentinel-node biopsy or nodal observation in melanoma. N Engl J Med 2006 355(13):1307-1317.

29. Gerling M, Meyer KF, Fuchs K, Igl BW, Fritzsche B, Ziegler A, Bader F, Kujath $P$, Schimmelpenning $H$, Bruch HP, et al: High Frequency of Aneuploidy Defines Ulcerative Colitis-Associated Carcinomas: A Comparative Prognostic Study to Sporadic Colorectal Carcinomas. Ann Surg 2010, 251(1):74-83.

30. Wang J, Kulaylat M, Rockette H, Hassett J, Rajput A, Dunn KB, Dayton M: Should total number of lymph nodes be used as a quality of care measure for stage III colon cancer? Ann Surg 2009, 249(4):559-563.

31. Hashiguchi $Y$, Hase K, Ueno H, Mochizuki H, Kajiwara Y, Ichikura T, Yamamoto J: Prognostic significance of the number of lymph nodes examined in colon cancer surgery: clinical application beyond simple measurement. Ann Surg 2010, 251(5):872-881.

32. Schrag D, Cramer LD, Bach PB, Cohen AM, Warren JL, Begg CB: Influence of hospital procedure volume on outcomes following surgery for colon cancer. JAMA 2000, 284(23):3028-3035. 


\section{Pre-publication history}

The pre-publication history for this paper can be accessed here:

http://www.biomedcentral.com/1471-230X/12/24/prepub

doi:10.1186/1471-230X-12-24

Cite this article as: Laubert et al: Metachronous metastasis- and

survival-analysis show prognostic importance of lymphadenectomy for colon carcinomas. BMC Gastroenterology 2012 12:24.

Submit your next manuscript to BioMed Central and take full advantage of:

- Convenient online submission

- Thorough peer review

- No space constraints or color figure charges

- Immediate publication on acceptance

- Inclusion in PubMed, CAS, Scopus and Google Scholar

- Research which is freely available for redistribution

Submit your manuscript at 